\title{
Development of Fiber-Reinforced Slag-Based Geopolymer Concrete Containing Lightweight Aggregates Produced By Granulation of Petrit-T
}

\author{
Mohammad Mastali $^{1^{*}}$, Katri Piekkari ${ }^{1}$, Paivo Kinnunen${ }^{1}$, and Mirja \\ Illikainen ${ }^{1}$ \\ ${ }^{1}$ Fibre and Particle Engineering, Faculty of Technology, Univ. of Oulu, P.O. Box 4300, 90014 \\ Oulu, Finland \\ *Corresponding Author: Mohammad.mastali@oulu.fi
}

This is a post-peer-review, pre-copyedit version of an article published in M. R. Taha (ed.), International Congress on Polymers in Concrete (ICPIC 2018). The final authenticated version is available online at: https://doi.org/10.1007/978-3-319-78175-4_73.

Using by-products as alternatives to ordinary Portland cement (OPC) is attracting growing attention in the sustainable construction material sectors. Alkali-activated binders have been proposed and emerged as an alternative to OPC binders, which seem to have acceptable mechanical and durability performances in addition to positive environmental impacts. These alternative binders also named "geopolymer", use a wide range of aluminosilicate precursors, with differing availabilities, reactivates, costs, and $\mathrm{CO}_{2}$ emissions. The usage of various materials results in obtaining the locally adaptable mix compositions, which establishes a broader toolkit. In this study, Petrit-T as a by-product from manufacturing sponge iron with fine particle-size distribution and rich in calcium was used to prepare the structural lightweight aggregates. Moreover, ground granulated blast-furnace slag (GGBFS) as the binder was activated by a combination of sodium hydroxide and sodium silicate as the alkali activator. The effects of using different fiber types, including PVA, PP, and basalt, on mechanical properties were investigated. Mechanical properties were addressed in terms of the compressive and flexural strengths. The results showed that reinforcing the composition significantly affected the flexural performance. Moreover, it was revealed that using the granulated Petrit-T presented a lightweight concrete, with density $\rho \leq 1600 \mathrm{~kg} / \mathrm{m}^{3}$.

\section{Introduction}

Alkali activated slag cements are one of the activated cementitious materials, which is produced by using waste product of steel companies and are rich in calcium content. These materials have shown great potential to reach high compressive strength 
at early age, great durability performance especially against chemical (acid and sulfate) attacks, rapid setting and hardening, low hydration heat, high temperature resistance, and lower $\mathrm{CO}_{2}$ emission compared to OPC [1-3]. These materials still have some drawbacks such as volumetric instability and the high drying shrinkage compared to OPC. Various solutions proposed to minimize the drying shrinkage in the alkali activated slag cements such as using fibers as one of the most effective ways. Nevertheless, fibers could also have different effects on mechanical characteristics of the reinforced mix compositions, regarding the fiber type, length, and content. Therefore, an experimental investigation was executed in the present paper to clarify the effects of using different fibers on mechanical properties and forming cracks due to large drying shrinkage (visually). Moreover, lightweight aggregates were used in the mixtures to reduce the density. These aggregates were produced by alkali activation of Petrit-T by-product.

\section{Experimental program}

The geopolymeric mortars were prepared through mixing slag, structural aggregates, and alkaline activator. The structural aggregates were prepared by mixing pre-wetted Petrit-T, sodium silicate with silica modulus of 2.5 , borax as retarders. To prepare the structural aggregates, the ingredients were granulated using an Eirich high-intensity mixer for 2-3 minutes, similarly to earlier alkali granulation. Afterward, the aggregates were covered with plastic bags for $24 \mathrm{~h}$. Figure 73.1 depicts the particle size distributions of the granulated Petrit-T. Moreover, the density of the aggregates was measured to be lower than $900 \mathrm{~kg} / \mathrm{m}^{3}$. The lightweight structural aggregates should meet the requirements of the ASTM C 330 recommendation, which bulk density should be less than $1120 \mathrm{~kg} / \mathrm{m}^{3}$ for fine aggregates and less than $880 \mathrm{~kg} / \mathrm{m}^{3}$ for coarse aggregates [4]. Thus, the granulated Petrit-T could be classified as the structural lightweight aggregates. The binder consisting of ground granulated blast-furnace slag as the binder was activated by a combination of sodium hydroxide and sodium silicate as the alkali activator with a ratio of 2 . The $\mathrm{NaOH}$ solution was also prepared through dissolving $\mathrm{NaOH}$ pellets in water with a molar concentration of $12 \mathrm{~mol} / \mathrm{L}$ and cooled down to room temperature. Sodium silicate solution was used as a liquid sodium silicate with modulus of 2.5 (molar ratio $\mathrm{SiO}_{2} / \mathrm{Na}_{2} \mathrm{O}=\mathrm{M}$ ). The alkali activator to binder ratio was equal to 0.56 .

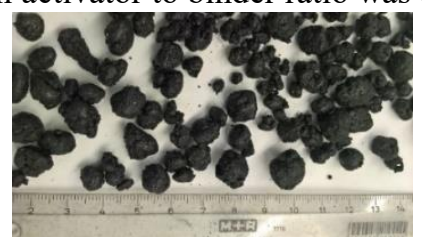

Fig. 73.1 The granulated Petrit-T using Eirich high intensity mixer

Previous researches have demonstrated that the drying shrinkage of the alkali-activated slag binders could be much higher than cementitious compositions or other alkali activated binders [5-6]. Large drying shrinkage results in crack formation, 
which significantly affects mechanical and durability performances of the binders. Using fibers is one of the most effective solutions to control the drying shrinkage, since it not only reduces the drying shrinkage but also improves mechanical characteristics. Therefore, three different fibers (basalt, polypropylene (PP), polyvinyl alcohol (PVA)) were employed to reinforce the mixture in order to control shrinkage and enhance mechanical properties. The fiber content used to reinforce the mixtures was constant and equal to $2 \%$ of binder mass. The physical and mechanical properties of the fibers are listed in Table 73.1. Additionally, the used fibers are shown in Fig. 73.2a.

Table 73.1 The physical and mechanical properties of the fibers

\begin{tabular}{cccccc}
\hline Fiber type & $(\mathrm{L} / \mathrm{D})$ & $\begin{array}{c}\text { Elastic } \\
\text { modulus } \\
(\mathrm{GPa})\end{array}$ & $\begin{array}{c}\text { Tensile } \\
\text { strength } \\
(\mathrm{MPa})\end{array}$ & $\begin{array}{c}\text { Elongation } \\
\text { at break } \\
(\%)\end{array}$ & $\begin{array}{c}\text { Density } \\
\left(\mathrm{g} / \mathrm{cm}^{3}\right)\end{array}$ \\
\hline PVA & 200 & 41 & 1600 & 6 & 1.3 \\
PP & 833 & 9.6 & 910 & $<12$ & 0.91 \\
Basalt & 333 & 100 & 4500 & 3.1 & 2.63 \\
\hline
\end{tabular}

In the batching process of the mixtures, slag $(530 \mathrm{~g} / \mathrm{L})$ was mixed with the lightweight aggregates $(530 \mathrm{~g} / \mathrm{L})$ for $1 \mathrm{~min}$. The alkali-activated solution $(297 \mathrm{~g} / \mathrm{L})$ was then added, and the obtained mixture was remixed for 2 min. Finally, the fiberreinforced mixtures were prepared through gradually adding the fibers to the fresh mixture while mixing as long as desirable percentages of fiber are reached. During the preparation of the mixture, the fibers were gradually added to avoid balling. Afterward, the mixtures were cast into the prismatic beams $(40 \times 40 \times 160 \mathrm{~mm})$, demolded after $24 \mathrm{~h}$ and covered with plastic until the age of 28 days. Mechanical properties were characterized by measuring the compressive and flexural strength.

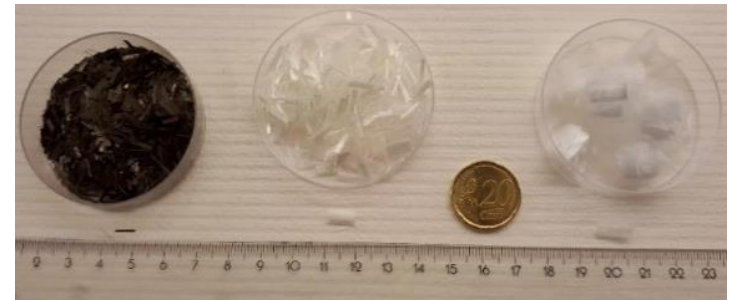

a)

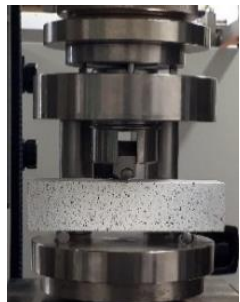

b)

Fig 73.2 (a) The used fiber in reinforcing the mixtures; (b) device to execute the flexural strength test

Prismatic beams were cast and tested under three point bending (TPB) load conditions regarding the ASTM C78 recommendation [7]. The flexural load was submitted to the beams with a displacement rate of $0.6 \mathrm{~mm} / \mathrm{min}$, and the flexural load was measured using a load cell of $1000 \mathrm{kN}$ capacity. For each mix composition, the flexural strengths represent the average of three replicated prismatic beams. The 
compressive test was carried out on the prisms broken in the flexural test according to the ASTM C349 recommendation [8]. The compressive load was imposed to the beams with a displacement rate of $1.8 \mathrm{~mm} / \mathrm{min}$. The compressive strengths of the compositions were obtained by averaging six prisms broken in the flexural test.

\section{Results and discussion}

The influences of using fibers on mechanical properties are illustrated in Fig. 73.3. Regarding the results, the addition of fibers (regardless of the fiber type) increased the compressive strength. The addition of fiber increases the air voids in the mixture, and at the same time, fibers can limit the propagation of cracks. The interaction of these two effects could either increase or decrease the compressive strength. On the other hand, the addition of fibers could limit the further crack propagation, and subsequently, the compressive strength increased. As depicted in Fig. 73.3a, the minimum and maximum increase of the compressive strength compared to the plain mixture were recorded about $10 \%$ and $35 \%$ for the reinforced mixtures with basalt and PVA fibers, respectively. Fiber bridging action transfers the tensile stress across crack, and this phenomenon leads to increasing the flexural strength in the fiberreinforced mixtures. According to the results obtained in Fig. 73.3b, c, it was revealed that the minimum and maximum improvements in the flexural strength compared to the plain mixture were measured around $25 \%$ and 4 times in the reinforced mixtures with PP and PVA fibers, respectively. After forming the initial crack, a deflection hardening behavior observed in the reinforced matrix with PVA, as showed in Fig. 73.3b.

The surface of the fibers is covered by hydrated particles due to the excellent bond of PVA fibers to matrix, as shown in Fig. 73.4a. Fewer hydration products covered the surfaces of PP and basalt fibers, which could be justified by the smoother surfaces of fibers compared to PVA fiber. The reinforced mixtures with basalt fibers indicated a brittle behavior after forming the initial crack, and they suddenly entered the softening phase, which may be caused by short length of basalt fibers. The reinforced mixtures with PP fibers presented an almost linear behavior to form the initial crack at the flexural stress of $2.5 \mathrm{MPa}$, followed by an almost perfectly plastic behavior up to a mid-span deflection of about $4.5 \mathrm{~mm}$. This behavior could be explained by debonding of long PP fibers from its surrounded matrix. Regarding the result in Fig. 73.3d, except the mixtures containing PP fiber, introduction of PVA and basalt fibers had no great impact on reducing the stiffness. Using PP fibers decreased the stiffness more than $50 \%$, which could be due to increase of porosity. Furthermore, it is worth stating that no crack was visually monitored on the surface of the specimens reinforced with fibers, due to the drying shrinkage. This finding demonstrates that fibers were successful at mitigating the negative effects of drying shrinkage. 


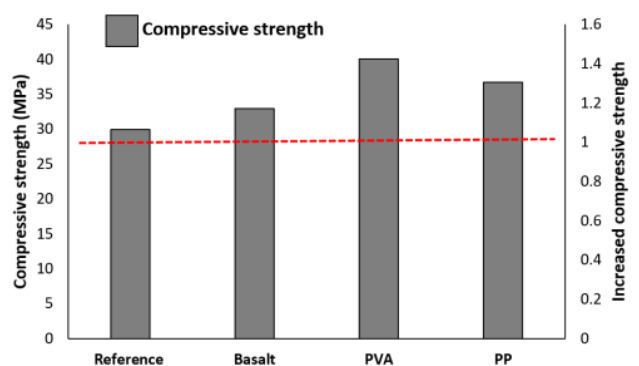

a)

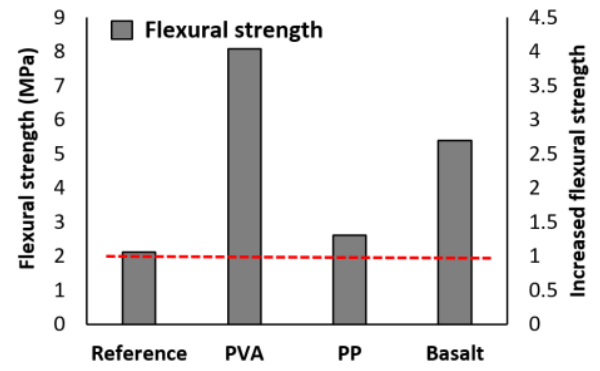

c)

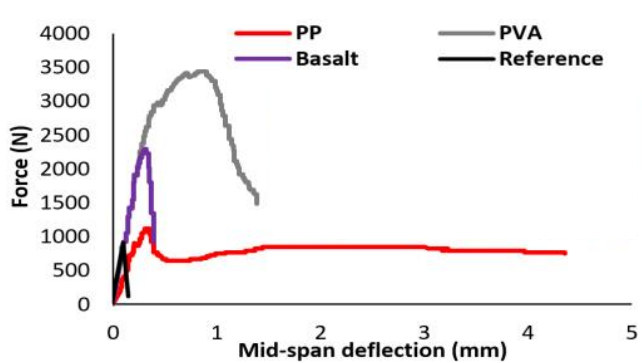

b)

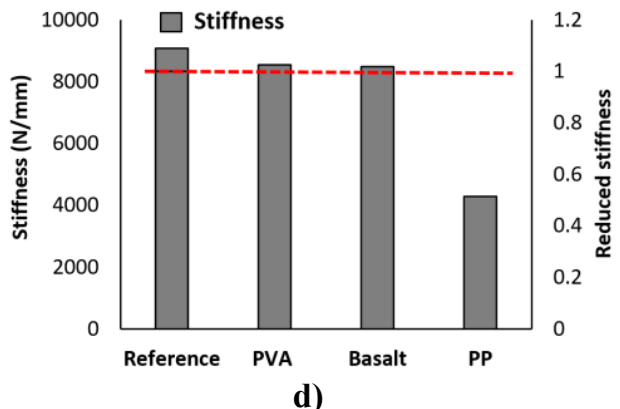

d)

Fig. 73.3 Effects of fiber on the (a) compressive strength, (b) force-deflection, (c) flexural strength, (d) stiffness

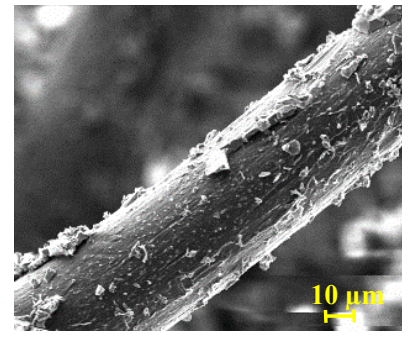

a)

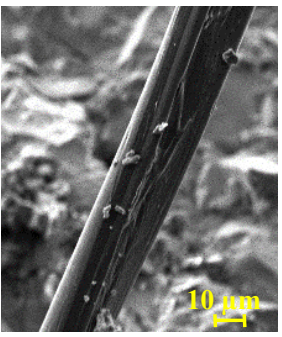

b)

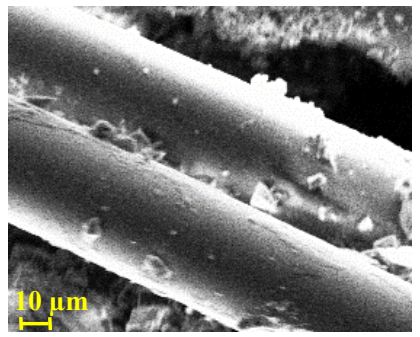

c)

Fig. 73.4 SEM images from the surfaces of (a) PVA fiber, (b) PP fiber, (c) basalt fiber

\section{Conclusion}

This paper presents results from an experimental investigation on mechanical properties of slag-based geopolymer concrete containing lightweight aggregates produced by alkali-granulation of Petrit-T. The geopolymeric mixtures were reinforced 
by three different fibers, PVA, PP, and basalt. Mechanical properties were addressed in terms of their compressive and flexural strength. Regarding the results reported in this study, the following conclusions could be drawn:

1. Regardless of fiber type, the addition of fibers increased both compressive and flexural strengths.

2. PVA fibers indicated the greatest impact on enhancing mechanical properties compared to other fibers, which was caused by efficient bonding with the matrix.

3. After forming the initial crack, a hardening deflection behavior observed for the reinforced mixtures with PVA fiber, while the reinforced mixtures with basalt and PP indicated softening and almost perfectly plastic behavior, respectively.

4. Using hybrid PVA/PP fibers could significantly reduce the material costs and increase the ductility of the fiber-reinforced mixtures. Therefore, further investigations on using hybrid fibers to obtain higher ductility with lower material costs are warranted using these materials.

\section{Acknowledgements}

The study presented in this paper is a part of the research project "MINPET: mineral products from Petrit-T sidestream" that has received funding from the EIT RawMaterials, under grant agreement No. EIT/ EIT RAW MATERIALS/SGA2016/1.

\section{References}

[1] Ye, H., Cartwright, C., Rajabipour, F., \& Radlinska, A. (2014). Effect of dying rate on shrinkage of alkali -activated slag cements. 4th International Conference on the Durability of Concrete Structures, 24-26 July 2014, Purdue University, West Lafayette, USA.

[2] Collins, F.G., \& Sanjayan, J.G. (1999). Workability and mechanical properties of alkali activated slag concrete. Cement and Concrete Research, 29, 455-458.

[3] Atiş, C.D., Bilim, C., Çelik, Ö., \& Karahan, O. (2009). Influence of activator on the strength and drying shrinkage of alkali-activated slag mortar, Construction and Building Materials, 23, 548555.

[4] ASTM C330 / C330M-17a, Standard Specification for Lightweight Aggregates for Structural Concrete, ASTM International, West Conshohocken, PA, 2017.

[5] Abdollahnejad, Z., Mastali, M., Mastali, M. \& Dalvand, A. (2017). A comparative study on the effects of recycled glass fiber on drying shrinkage rate and mechanical properties of the self-compacting concrete and fly ash/slag geopolymer concrete., Journal of Materials in Civil Engineering, 10.1061/(ASCE)MT.1943-5533.0001918.

[6] Askari, M.A., Mastali, M., Dalvand, A., Abdollahnejad, Z., (2017). Development of deflection hardening cementitious composites using glass fibres for flexural repairing/strengthening concrete beams: experimental and numerical studies, European Journal of Environmental and Civil Engineering, DOI: 10.1080/19648189.2017.1327888.

[7] ASTM C78 / C78M-16, Standard Test Method for Flexural Strength of Concrete (Using Simple Beam with Third-Point Loading), ASTM International, West Conshohocken, PA, 2016.

[8] ASTM C349-14, Standard Test Method for Compressive Strength of Hydraulic-Cement Mortars (Using Portions of Prisms Broken in Flexure), ASTM International, West Conshohocken, PA, 2014. 